\title{
Transactivation by body burden dioxin of herpes simplex virus genes and cytokines genes can weaken the host antiviral defense
}

\begin{abstract}
Among several common human viruses, the neurotropic HSV-1 was suggested a target of host cell dioxin receptor transcriptional (AhR-Arnt) complex. The latter was proven to up-regulate the expression of mammalian and viral genes containing multiple dioxin-responsive elements (DRE). Here, 7 to 8 potentially active DRE in the regulatory regions of five $\mathrm{HSV}-1$ genes, including critical immediate-early (IE) ones, were revealed by SITECON, a tool for transcription factor binding sites recognition. With regard to the possession of abundant promoter DRE, HSV-1 resembles another herpes virus, CMV, and as well as with CMV, it was experimentally demonstrated that the HSV-1 might be trans-activated in host cells by concentrations of 2,3,7,8TCDD corresponding to current body burden of dioxin in general population. The above approach was applied also to chemokines and cytokines the recruitment of those involves in the first line of defense against HSV-1 infections together with production of IFN- $\alpha / \beta$. Thus in cilico studies revealed that genes encoding "antiviral" IFN- $\gamma$, IL-1 $\beta$, IL-6, IL-18, NF-kB1 (p50), TNF- $\alpha$ each contain just one or two promoter DRE, whereas genes encoding "pro-viral" RANTES/CCL5, NF-kB3/p65/RelA and STAT3 possess seven to nine active 5'-upstream DRE. As virus-host interactions are crucial for the outcome of infections, our findings of multiple potentially active DRE in promoter region of HSV-1 genes, as well as in genes encoding major host cell "pro-viral" cytokines, this suggests that a subnanomolar dioxin in host cell is able to promote HSV-1 infection. From a clinical standpoint, an inhibition of dioxin can cause augmentation of HSV-1 infections which can be achieved with inhibitors of dioxin binding to host cell Ah receptor, or blockage of activated AhR-Arnt transcriptional complex binding to the viral promoter DRE.
\end{abstract}

Keywords: HSV-1, pro-viral, neurotrophic, cytokines, DNA virus
Volume 4 Issue 3 - 2017

\author{
Tsyrlov IB,' Wu JS,' Oshchepkov DY² \\ 'XENOTOX Inc, USA \\ 2Institute of Cytology \& Genetics, Russian Academy of Science, \\ Russia
}

Correspondence: Tsyrlov IB, XENOTOX Inc, USA Email xenotoxit@optonline.net

Received: May 16, 2017 | Published: June 16, 2017

\section{Introduction}

Some common viruses have been suggested novel target genes of host cell dioxin receptor transcriptional (AhR-Arnt) complex firstly proven to upregulate the expression of mammalian genes containing dioxin-responsive elements (DRE). ${ }^{1}$ The concept emerged from our discovery of direct transactivation of the human immunodeficiency virus and hepatitis B virus in target human cells by 30-300ppt dioxin..$^{1,2}$ Upregulation of cytomegalovirus in human cells was demonstrated at dioxin concentrations of 0.1-0.3ppt, i.e., lower than its current background level in the general population $(\sim 3.0 \mathrm{ppt}){ }^{3,4}$ Going along with the experimental data, multiple potentially active DRE were computationally detected and quantified in regulatory area of several human viruses. ${ }^{4,5}$ In this study, a computational search for DRE in HSV-1 genes was performed using approach SITECON ${ }^{6}$ designated for recognition of transcriptional factor binding sites. HSV-1 is a DNA virus causing diseases ranging from simple cold sores to lethal encephalitis. ${ }^{7}$ It is well-adapted common pathogen with worldwide Seroprevalence rates ranging from $50 \%$ to $90 \%$, which hiding in our neurons for life. However, factors initiating in rare situations the expression of HSV-1 lytic cycle from the latent viral genome and leading to generalized infection are still not known. ${ }^{8}$ The first line of defense against HSV- 1 infections involves production of IFN- $\alpha / \beta$ and activation of the innate immune response by recruitment chemokines and cytokines. To this point, we previously used SITECON to determine potentially active promoter DREs in genes encoding proinflammatory cytokines and macrophage transcriptional factors. ${ }^{9}$ Experimentally, nanomolar concentrations of dioxin activated IL-1 $\beta$ mRNA synthesis in human monocytes, ${ }^{10}$ and caused up regulation of COX-2, IL-8 and TNF- $\alpha$ genes in U937 macrophages. ${ }^{11}$ Here, to comprehend whether current body burden level of dioxin may affect host defense factors against HSV-1, we quantitated potentially active DREs in macrophage antiviral factors genes, as well as cytokines genes whose expression might be affected by host cell AhR-Arnt transcriptional complex.

\section{Materials and methods}

A total of 13 bona fide DREs, all including the substitution intolerant core sequence (5'-GCGTG-3') and adjacent variable sequences, were used as a training sample to detect conservative conformational and physico-chemical properties for the site with DRE, and to construct the recognition rules and determine conformational similarity score threshold to rank identified DREs. We used the approach utilized for mammalian DREs5, but the recognition threshold of 0.95 , for which type I error equal to zero, i.e., the condition when SITECON employed conformational similarity score6 allowing recognize all sites in the training sample. Earlier, an efficacy of SITECON in detection of functionally active DREs was tested using sequences of genes encoding human CYP1A1 and CYP1B18, which was also proven 
experimentally. ${ }^{12}$ It was demonstrated that at the recognition threshold of 0.95 , SITECON efficiently identified all tested functionally active DREs. ${ }^{13}$ In fact, promoter DREs within genes encoding AhR, HSP90, $\mathrm{XAP} 2$, and macrophage proinflammatory factors were detected by SITECON with high scores of 0.974-0.987..$^{9,14}$

\section{Results and discussion}

Earlier, computational data from Zacharewsky $1 \mathrm{ab}^{5}$ demonstrated 30 DRE core sequences in 5'-flanking region of the HSV-1 genes. However, the DREs were recognized with a MS score of 0.8357 that was even lower than accepted threshold $(0.85)$ for their study and much lower than recognition threshold of 0.95 in current study. Here, as Table 1 show, within five HSV-1 genes, including critical immediate-early (IE) ones, SITECON detected 7 to 8 potentially active DREs in the regulatory regions. Also, several other HSV-1 genes (b' ICP, IE-III, b' gB 3.3kb, b' gE, [U-S] b' tr-4) also possess at least 6 promoter DREs. Earlier, almost equal number of promotor DRE (ten) was computationally recognized in another human herpes virus, cytomegalovirus ${ }^{5}$ (in our study, 7 to10). Such abundance of DRE elements in regulatory regions of the virus was directly associated with its multifold transcriptional upregulation by dioxin concentration of $10 \mathrm{ppq}$ in human fibroblast line, ${ }^{3}$ and $30 \mathrm{ppq}$ - in human monocytic cell line. ${ }^{4}$ The demonstrated analogy between genes of cytomegalovirus and HSV-1, with regard to their abundant promoter DREs, strongly suggests current body burden of dioxin in general population $(\sim 3 \mathrm{ng} /$ $\mathrm{kg}$, lipid $)^{14}$ as a reasonable trigger of HSV-1 activation via host cell AhR-Arnt transcriptional pathway. Presumably binding of activated AhR-Arnt complex at the viral promoter DRE might occur while the HSV-1 progeny is formed in the nucleus of the infected cell, and viral DNA is packed into preformed capsids.

Table I Potentially active promoter DREs detected by SITECON in Herpes Simplex Virus I genes

\begin{tabular}{|c|c|c|c|c|c|}
\hline Virus name & Gene names (range -3000 to 100 ) & Site position & Score & Direction & Site sequence \\
\hline \multirow{8}{*}{ HSV-I } & \multirow{8}{*}{ b'g' $2.1 \mathrm{~kb}$} & -2981 & 0.977 & direct & CTCCAGCGTGCCGT \\
\hline & & -2669 & 0.967 & indirect & AAGGGGCGTGATTT \\
\hline & & -2324 & 0.974 & indirect & GTCTCGCGTGCCCA \\
\hline & & -1799 & 0.971 & indirect & CGTTGGCGTGCACC \\
\hline & & -1486 & 0.971 & direct & GATGCGCGTGAGGG \\
\hline & & -566 & 0.985 & indirect & TCGCTGCGTGCTGC \\
\hline & & -321 & 0.972 & indirect & ACAGCGCGTGCCGC \\
\hline & & -23 & 0.973 & indirect & CGGTGGCGTGCTGA \\
\hline \multirow{7}{*}{ HSV-I } & \multirow{7}{*}{ g' gC } & -2654 & 0.977 & indirect & AACCAGCGTGCGAA \\
\hline & & -1413 & 0.967 & direct & GTGGGGCGTGACGG \\
\hline & & -1395 & 0.974 & direct & ACCCCGCGTGCCAT \\
\hline & & $-129 \mid$ & 0.974 & direct & ACCTCGCGTGCGTG \\
\hline & & -1287 & 0.955 & direct & CGCGTGCGTGGGGG \\
\hline & & -1030 & 0.985 & indirect & CGGCTGCGTGCCGG \\
\hline & & -379 & 0.967 & indirect & GTCCGGCGTGAACA \\
\hline \multirow{7}{*}{ HSV-I } & \multirow{7}{*}{ IE-IV/V } & 43 & 0.973 & indirect & GGTCCGCGTGCTCC \\
\hline & & -2847 & 0.97 & direct & CGTCGGCGTGCGGC \\
\hline & & -2337 & 0.972 & direct & CCGCCGCGTGCGCC \\
\hline & & -2126 & 0.974 & direct & CAGCCGCGTGATCA \\
\hline & & -1639 & 0.969 & indirect & GCCTCGCGTGCGTG \\
\hline & & -1635 & 0.955 & direct & CGCGTGCGTGGTCG \\
\hline & & -554 & 0.971 & indirect & CCCCGGCGTGCCGG \\
\hline \multirow{7}{*}{ HSV-I } & \multirow{7}{*}{ b’ 82K AlkExo } & -2277 & 0.975 & direct & GACACGCGTGCGAC \\
\hline & & -1438 & 0.986 & indirect & GTCTTGCGTGACGA \\
\hline & & -1386 & 0.977 & direct & GCCCAGCGTGCGAT \\
\hline & & -1032 & 0.953 & direct & CTACTGCGTGGGCC \\
\hline & & -823 & 0.954 & direct & GTTTTGCGTGGCCG \\
\hline & & -386 & 0.973 & direct & CGGTGGCGTGCTGA \\
\hline & & -88 & 0.972 & direct & ACAGCGCGTGCCGC \\
\hline
\end{tabular}


Table Continued....

\begin{tabular}{|c|c|c|c|c|c|}
\hline Virus name & Gene names (range -3000 to 100 ) & Site position & Score & Direction & Site sequence \\
\hline \multirow{7}{*}{ HSV-I } & \multirow{7}{*}{ [U-S] b' tr-9 } & $-24 I I$ & 0.986 & indirect & GGCGTGCGTGACGA \\
\hline & & -2407 & 0.97 & indirect & CATTGCCGTGCGTG \\
\hline & & -1743 & 0.956 & direct & ATGCGGCGTGCATG \\
\hline & & -1345 & 0.968 & direct & CATGTGCGTGGGGT \\
\hline & & -900 & 0.968 & indirect & CCCAGGCGTGAATA \\
\hline & & -664 & 0.97 & direct & CGCAGGCGTGCCTG \\
\hline & & -56 & 0.955 & direct & GGATTGCGTGGTAT \\
\hline
\end{tabular}

It is widely accepted that during productive infection HSV1 efficiently hampers the ability of the host to mount an antiviral response and in this way promotes the establishment of infection. Thus, although HSV-1 IE gene induces transcription of genes encoding proinflammatory cytokines, IE own proteins are capable to destabilize virus-induced cellular mRNAs, which results in only modest production of the cytokines7. The first line of defense against HSV- 1 involves production of IFN- $\alpha / \beta$ and activation of the innate immune response, ${ }^{8}$ and virus itself induces expression of chemokine RANTES/CCL5 in host cell. ${ }^{15}$ Table 2 shows that primarily responding to HSV-1 infection cellular factors and cytokines all possess DREs in regulatory region of their genes. However, a number of potentially active DREs are dramatically different. Thus genes encoding IFN- $\gamma$, IL-1 $\beta$, IL-6, IL-18, NF-kB1 (p50), TNF- $\alpha$ each contains just one or two promoter DRE, whereas genes encoding RANTES/CCL5, NF$\mathrm{kB} 3 / \mathrm{p} 65 /$ RelA and STAT3 possess seven to nine active 5' upstream
DREs, which make these genes more susceptible to dioxin-AhRArnt transcriptional complex. It is demonstrated that HSV-1 suppresses production of cytokines exerting their effects at initial stages of the antiviral response, namely IFN- $\alpha / \beta$, TNF- $\alpha$, IL- 6 , and IL-12. ${ }^{7,8}$ Traditionally, production of the above "first line" cytokines is regulated by chemokines, including RANTES. ${ }^{16}$ However, HSV1 might induce expression RANTES in infected cells ${ }^{15}$ and the induction is regulated by NF-kB/p65/RelA, ${ }^{17}$ which is recruited to viral promoter and persisted for several hours. Thus, new level of control of cellular functions by HSV-1 suggests that persistent NF$\kappa \mathrm{B} / \mathrm{p} 65 /$ RelA activation in HSV-1-infected cells, rather than being a host response to the virus, may play a positive role in promoting efficient viral replication. ${ }^{18}$ As for STAT3, its signaling was shown to promote oncolytic HSV-1 replication, likely by inhibiting the IFN- $\gamma$ response. $^{19}$

Table 2 Promoter DREs detected in genes encoding cytokines and macrophage transcription factors

\begin{tabular}{|c|c|c|c|c|c|}
\hline Gene name & Gene product/synonym & Site position & Score & Direction & Site sequence \\
\hline IL-Ib & & -1250 & 0.968 & indirect & TACAGGCGTGAGCC \\
\hline \multirow{2}{*}{ NF-kBI } & \multirow{2}{*}{ p50/ pl05 } & 157 & 0.985 & indirect & TGGCTGCGTGCAGG \\
\hline & & -65 & 0.985 & direct & CCGCTGCGTGCGCG \\
\hline \multirow{5}{*}{ NF-kB2 } & \multirow{5}{*}{ p49/pl00/ p52 } & 540 & 0.976 & direct & GGGGAGCGTGCAGA \\
\hline & & 313 & 0.985 & indirect & TTTGTGCGTGAAGG \\
\hline & & -132 & 0.967 & indirect & GCGAGGCGTGACGC \\
\hline & & -1125 & 0.969 & indirect & CAGTGGCGTGATCA \\
\hline & & $-477 \mid$ & 0.969 & indirect & CAGTGGCGTGATCA \\
\hline \multirow{9}{*}{ NF-kB3 } & \multirow{9}{*}{ p65/ RelA } & 426 & 0.97 & direct & GTGGGGCGTGCCCT \\
\hline & & 24 & 0.97 & indirect & CCGCGGCGTGCACT \\
\hline & & -110 & 0.97 & direct & GCGCGGCGTGCACT \\
\hline & & -137 & 0.987 & direct & GCTGTGCGTGCAGC \\
\hline & & -199 & 0.972 & indirect & GGCTGGCGTGCCCG \\
\hline & & -1759 & 0.968 & indirect & TACAGGCGTGAGCC \\
\hline & & -3072 & 0.969 & indirect & TACAGGCGTGAGCT \\
\hline & & -3703 & 0.976 & indirect & TAACAGCGTGCACC \\
\hline & & -4985 & 0.968 & indirect & TACAGGCGTGAGCC \\
\hline \multirow{2}{*}{ IFN-Y } & & -1783 & 0.969 & direct & GAATGGCGTGAATC \\
\hline & & -1979 & 0.968 & indirect & TACAGGCGTGAGCC \\
\hline ILI8 & & -2704 & 0.968 & indirect, & AGAAGGCGTGATTC \\
\hline
\end{tabular}


Table Continued....

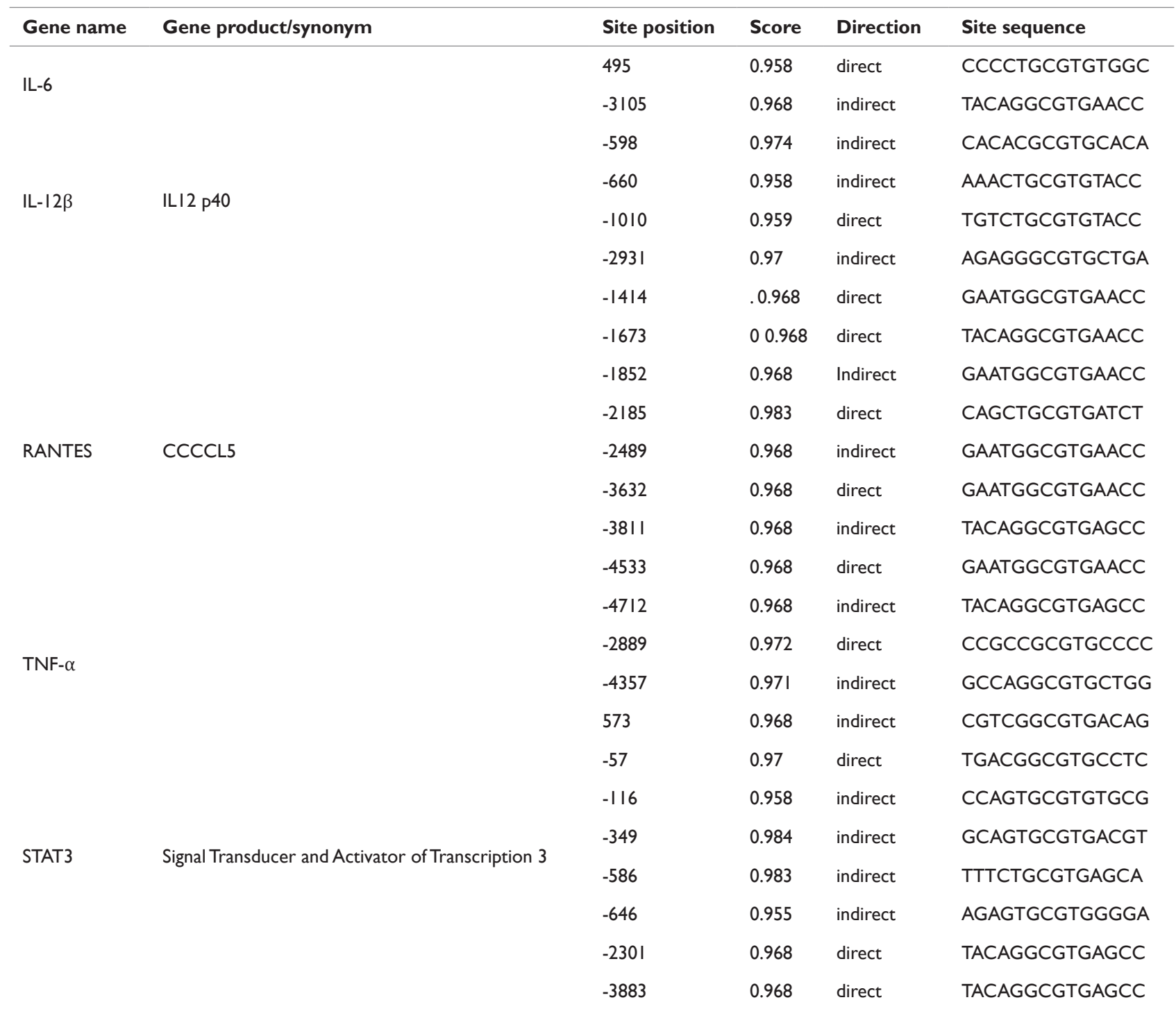

As virus-host interactions are crucial for the outcome of infections, our computational findings of multiple potentially active DREs in promoter region of HSV-1 genes, as well as in genes encoding major host cell cytokines, all strongly suggest that body burden subnanomolar dioxin is able to promote HSV-1 infection.

Noteworthy to this respect are epidemiological data that during last decade's proportion of newly diagnosed genital herpes infections resulting from HSV-1 increased from $31 \%$ to $78 \%$. Also, genital herpes infections in human population reflect a reversal of the usual HSV-1/HSV-2 ratio $^{20}$ (what is in full accordance with SITECON revelation that HSV-2 genes lack any potentially active promoter DRE). From a clinical standpoint, we initiated development of newly approach to (partial) inhibition of dioxin-caused augmentation of HSV-1 infections by using inhibitors blocking binding of dioxin to host cell Ah receptor, or binding of activated AhR-Arnt transcriptional complex at the viral promoter DREs. Clinically proven medicines such as coplanar bioflavonoids and salycilamide are among the candidate inhibitors. ${ }^{2,4}$

\section{Acknowledgements}

None.

\section{Conflict of interest}

The author declares no conflict of interest.

\section{References}

1. Pokrovsky AG, Chernukh AI, Yastrebova ON, et al. A Proposed Mechanism of Transactivation by Body Burden Dioxin of Herpes Simplex Virus Genes Might be Responsible for Weakening the Host Antiviral Defense. Biochem Biophys Res Commun. 1991;179:46-51.

2. Tsyrlov IB. Organ halogen Comp. 2006;68:552-555.

3. Murayama T, Inoue M, Nomura T, et al. 2,3,7,8-Tetrachlorodibenzo-pdioxin is a possible activator of human cytomegalovirus replication in a human fibroblast cell line. Biochem Biophys Res Commun. 2002;296:651-656.

4. Wu JS, Shur IN, Tsyrlov IB. Organ halogen Comp. 2008;70:1471-1474.

5. Sun YV, Boverhof DR, Fielden MR, et al. Comparative analysis of dioxin response elements in human, mouse and rat genomic sequences. Nucleic Acids Res. 2004;32(15):4512-4523.

6. Oshchepkov D, Grigovich D, Ignatieva E, et al. Nucleic Acids Res. 2004;32:W208-W212. 
7. Whitley RJ. Herpes simplex virus. In Fields virology. 2001:2461-2509.

8. Thompson R, Sawtell N. Evidence that the Herpes Simplex Virus Type 1 ICP0 Protein Does Not Initiate Reactivation from Latency in Vivo. $J$ Virol. 2006;80:10919-10925.

9. Oshchepkova E, Furman D, Oshchepkov D, et al. Organ halogen Comp. 2008;70:1467-1470.

10. Lozovatskiy A, Mordvinov V, Kuprianova O, et al. Organ halogen Comp. 1990;1:189-192.

11. Vogel CFA, Sciullo E, Wong P, et al. Environ Health Persp. 2005;113:1536-1541.

12. Tsuchiya Y, Nakajima M, Yokoi T. Critical Enhancer Region to Which AhR/ARNT and Sp1 Bind in the Human CYP1B1 Gene. J Biochem (Tokyo). 2003;133(5):583-952.

13. Nedosekina E, Oshchepkov D, Katokhin A, et al. Organ halogen Comp. 2007;69:1889-1892.

14. Aylward L, Hayes S. Temporal trends in human TCDD body burden: Decreases over three decades and implications for exposure levels. Expo Anal Environ Epidemiol. 2002;12(5):319-328.
15. Melchjorsen J, Pedersen FS, Mogensen SC, et al. Herpes Simplex Virus Selectively Induces Expression of the CC Chemokine RANTES/CCL5 in Macrophages through a Mechanism Dependent on PKR and ICP0. $J$ Virol. 2002;76(6):2780-2788.

16. Mogensen TH, Melchjorsen J, Casola A, et al. Suppression of Proinflammatory Cytokine Expression by Herpes Simplex Virus Type 1. J Virol. 2004;78(11):5883-5890.

17. Melchjorsen J, Paludan SR. Induction of RANTES/CCL5 by herpes simplex virus is regulated by nuclear factor $\kappa \mathrm{B}$ and interferon regulatory factor 3. J Gen Virol. 2003;84:2491-2496.

18. Amici C, Rossi A, Costanzo A, et al. Herpes Simplex Virus Disrupts NF$\kappa \mathrm{B}$ Regulation by Blocking Its Recruitment on the I $\kappa \mathrm{B} \alpha$ Promoter and Directing the Factor on Viral Genes. J Biol Chem. 2006;281:7110-7117.

19. Okemoto K, Wagner B, Meisen H, et al. STAT3 Activation Promotes Oncolytic HSV1 Replication in Glioma Cells. PLOS One. 2013;8(8):e71932.

20. Roberts CM, Pfister JR, Spear SJ. Increasing Proportion of Herpes Simplex Virus Type 1 as a Cause of Genital Herpes Infection in College Students. Sex Transm Dis. 2003;30(10):797-800. 